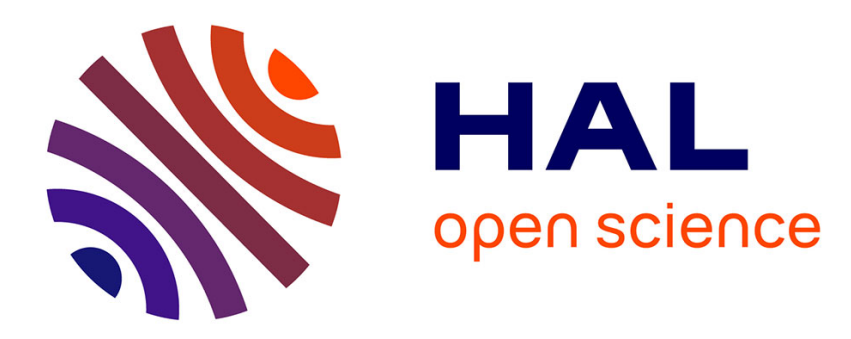

\title{
A pandemic business interruption insurance
}

Alexis Louaas, Pierre Picard

\section{To cite this version:}

Alexis Louaas, Pierre Picard. A pandemic business interruption insurance. 2020. hal-02941948

\section{HAL Id: hal-02941948 \\ https://hal.science/hal-02941948}

Preprint submitted on 17 Sep 2020

HAL is a multi-disciplinary open access archive for the deposit and dissemination of scientific research documents, whether they are published or not. The documents may come from teaching and research institutions in France or abroad, or from public or private research centers.
L'archive ouverte pluridisciplinaire HAL, est destinée au dépôt et à la diffusion de documents scientifiques de niveau recherche, publiés ou non, émanant des établissements d'enseignement et de recherche français ou étrangers, des laboratoires publics ou privés. 


\title{
A pandemic business interruption insurance
}

\author{
Alexis Louaas* and Pierre Picard ${ }^{\dagger}$
}

September 15, 2020

Abstract: We analyze how pandemic business interruption coverage can be put in place by building on capitalization mechanisms. The pandemic risk cannot be mutualized since it affects simultaneously a large number of businesses, and furthermore, it has a systemic nature because it goes along with a severe decline in the real economy. However, as shown by COVID-19, pandemics affect economic sectors in a differentiated way: some of them are very severely affected because their activity is strongly impacted by travel bans and constraints on work organisation, while others are more resistant. This opens the door to risk coverage mechanisms based on a portfolio of financial securities, including long-short positions and options in stock markets. We show that such financial investment allow insurers to offer business interruption coverage in pandemic states, while simultaneously hedging the risks associated with the alternation of bullish and bearish non-pandemic states. These conclusions are derived from a theoretical model of corporate risk management, and they are illustrated by numerical simulations, using data from the French stock exchange.

Keywords: pandemic, business interruption, insurance, corporate risk management.

JEL classification: G11, G22, G32.

*CREST-Ecole Polytechnique, France. E-mail : alexis.louaas@polytechnique.edu

${ }^{\dagger}$ CREST-Ecole Polytechnique, France. E-mail : pierre.picard@polytechnique.edu. Address for correspondence: Ecole Polytechnique, Department of Economics, 91128 Palaiseau Cedex, France.

Simulations presented in the paper have been realized in cooperation with Lou Saison (student at Ecole Polytechnique). We are very grateful to her for an outstanding contribution to the realization of these simulations. 


\section{Introduction}

Although the full extent of COVID-19 economic consequences is not yet perfectly known to date, there is no doubt that, in many countries, it has been at the origin of dramatic losses due to business interruption. Because of the pandemic, workers, customers and entrepreneurs were not in a position to pursue their activity normally, and therefore firms were prevented from conducting usual business operations 11 In this context, many firms turned to their insurance policies, in the hope that business interruption claims could be filed to recover losses resulting from the ongoing sanitary crisis. Business interruption coverage is typically included as part of a company's commercial property insurance policy, and is most commonly triggered when there is direct damage to insured property, particularly in case of fire or during natural disasters, such as floods, hurricanes or earthquakes. Contingent business interruption coverage can also apply when a government limits access to a specific geographic area, thereby impairing access to the policyholder's premises. However, for claims related with COVID-19, policy wording appears to be critical, and many insurers have denied coverage, by contending that claims do not meet the "direct physical loss" requirement contained within standard business interruption policies ${ }^{2}$

Court decisions reflect the diversity of situations and policy wordings, and we do not intend here to express a view on the validity of the arguments made by different parties ${ }^{3}$ There ought, however, to be agreement about the fact that insurers were not prepared to face such a pandemic risk. In practice, business interruption was merely viewed as an indirect loss induced by property damage, with specific loss evaluation principles, that should be covered through similar mutualization mechanisms. In the recent period, the emergence of cyber risk was a first reason for considering that the mutualization of business interruption risk could be undermined by common factors affecting the whole economy. COVID19 is another step in this direction, but with a much greater magnitude.

Put in simple terms, a worldwide pandemic is an insurance risk that cannot be covered by usual mutualization mechanisms, because it is characterized by a very large degree of correlation between policyholders. In other words, and at the risk of stating the obvious, characterizing an optimal pandemic insurance scheme requires that we start from the fact that a pandemic affects a large

\footnotetext{
${ }^{1}$ Estimates from the US Census Bureau (Buffington et al. (2020)) about the first phase of the pandemic show that $89.9 \%$ of small businesses have experienced a negative effect on operations due to the COVID-19, including $51.4 \%$ seeing a large negative effect and $38.5 \%$ a moderate negative effect. The large negative effect was especially pronounced in the Accommodation and Food Services industry where $83.5 \%$ of businesses experienced a large negative effect. In a survey of more than 5,800 small businesses conducted between March 28 and April 4, 2020, Bartik et al. (2020) find that $43 \%$ of the small businesses in their sample had temporarily closed and that businesses have - on average - reduced their employee counts by 40 percent relative to January. They document that mass layoffs and closures had already occurred, just a few weeks into the crisis, and they also find that many small businesses are financially fragile, with less than one month of cash on hand.

${ }^{2}$ See DBRS-Morningstar (2020).

${ }^{3}$ For a discussion of these issues, see French $(2020)$.
} 
number of individuals or businesses simultaneously. In other words, it would not make sense to look for a pandemic insurance scheme in which, as with most other property lines, the misfortunes suffered by a few policyholders would be compensated by the contributions of all the other ones. In this regard, while insurance pooling arrangements are part of the usual arsenal against catastrophic risks 4 they are not of great help here, since when a pandemic occurs, it is feared that it affects all the insurers in the pool. In other words, pandemic risks are correlated not only within an insurer's portfolio, but also between insurers.

A further question relates to the role of governments in guaranteeing the sustainability of a pandemic corporate insurance. Many think that national governments should ultimately backstop the insurance coverage, as is the case in the Terrorism Risk Insurance Act created in the U.S. in the aftermath of 9/11, but also in natural disaster insurance regimes existing in European countries, especially France and Spain. However, even with such a backstop, pandemic risk is considered by many insurers as too unwieldy and too potentially widespread for underwriting to take place. In other words, the insurability of the pandemic risk itself is in question.

In the limited framework of the present study, we will leave aside this important question of the role of governments, and we will focus attention on the issue of how the pandemic risk could be covered through insurance mechanisms. It is well-known that, in the usual activity of the insurance industry, the two basic insurance mechanisms, namely mutualization and capitalization, are relevant in areas that are clearly separated from one another: $\mathrm{P} \& \mathrm{C}$ lines and health insurance are based on mutualization, while life insurance works through capitalization. This dichotomy has to be abandoned when it comes to corporate pandemic insurance, since the coverage of business interruption is a key line of business of $\mathrm{P} \& \mathrm{C}$ insurers, but it cannot be mutualized in the case of pandemics. The objective of the present paper is to explore this avenue, by analyzing how capitalization mechanisms may yield business interruption coverage in the case of a pandemic.

At first sight, going through the capitalization channel conflicts with the systemic nature of the pandemic risk $5^{5}$ To put it in simple terms, the per-

\footnotetext{
${ }^{4}$ This includes terrorism risk (e.g., Pool Re in UK and GAREAT in France), flood risk (e.g., Flood Re in UK) and nuclear liability risk in the US and for signatory countries of Paris and Brussels international conventions.

${ }^{5}$ According to the definition of Cummins \& Weiss (2013), a systemic risk is "the risk that an event will trigger a loss of economic value or confidence in a substantial segment of the financial system that is serious enough to have significant adverse effects on the real economy with a high probability". In this definition, the transmission chain starts from an economic event, whatever it may be, that destabilizes the financial sector, and thereby induces a severe decline of the activity in the real sector. The collapse of the U.S. housing bubble that peaked in 2006, and was at the origin of a global credit crunch in 2007-2008, causing huge losses in stock markets, and that ultimately created a worldwide downturn in economic activity, is a typical example of such a sequence that goes from financial markets to the real economy. In the case of COVID-19, the causality chain is reversed, in the sense that the trigger affects the real sphere first (i.e., the pandemic has prevented many firms from carrying on their business in a normal manner), with effects that are widespread enough to affect the global economy, and ultimately the financial markets. Whatever the direction of causality, in both
} 
spective of suffering from a major macroeconomic downturn in the case of a pandemic does not make it easy to create risk sharing mechanisms to the benefit of firms suffering from business interruption. However, this concomitance between a well-defined event (mainly, the limited ability to move and to exert a normal business activity) causing severe corporate losses, and a macroeconomic crisis is too narrow a view that overlooks the uneven impacts of the pandemic throughout the economy. Pandemics affect sectors of the economy more or less, according to the effect of travel and work restrictions on their activity, while some of them may even take advantage of the situation. Tourism and restaurants, transportation and distribution, manufacturing and craft, entertainment industries, retail and luxury industries, and all industries based on international supply chain have been most severely penalized by COVID-19, while pharmaceutical and biotech industries, online BtoB and BtoC platforms and high-tech industries benefit either from the increase in demand for health care, or from changes in consumption patterns, or from the propensity of firms to reorganize their activity through a more intense use of digital tools.

These uneven effects of the current pandemic across sectors is reflected in stock market performances. A decomposition of the S\&P500 index at the industry level allows us to see these differential effects clearly. Panels a and b in Figure 1 display the evolution of several industry specific indices relative to the global S\&P500 index. While the aerospace and defense, airlines, automobiles, oil, gas and consumable fuels, banks and insurance indices experience a drop more important than the global index, industries such as biotechnologies, life sciences and tools, pharmaceutical, internet and direct marketing, software and food products fare relatively better. In France, the CAC40 index is a capitalization-weighted measure of the 40 most significant stocks on the Euronext Paris. In 2020, while the CAC40 has experienced a severe fall of $30 \%$ between January 1st and April 1st, the individual stock responses have presented a large degree of heterogeneity. Table A lists twelve stocks that have significantly under-performed the CAC40. With a drop of $64.1 \%$ of its quotation, the retail real estate trust UNIBAIL-RODAM-WESTFIELD suffered the largest loss, while its associated put options skyrocketed to provide a $807.92 \%$ return to their holders. The performance of all stocks listed in Table A is below that of the media group PUBLICIS, that lost $35 \%$ of its value in four months. Table B in contrast, lists twelve French stocks that have relatively well resisted to the COVID-19 shock. The luxury brand Hermes even won two percent on its quotation and its associated calls increased by $10.40 \%$. At the bottom of the table, LVMH, another company from the luxury sector, lost "only" $15 \%$ while its associated call options lost $14 \%$.

cases the risk is said to be systemic because it affects the real and financial spheres of the global economy, and not only a limited number of victims. Natural disasters (at least, those we have experienced so far) are not systemic, although they may be at the origin of dramatic losses for the population concerned. 



(a) Under-performing sub-indices
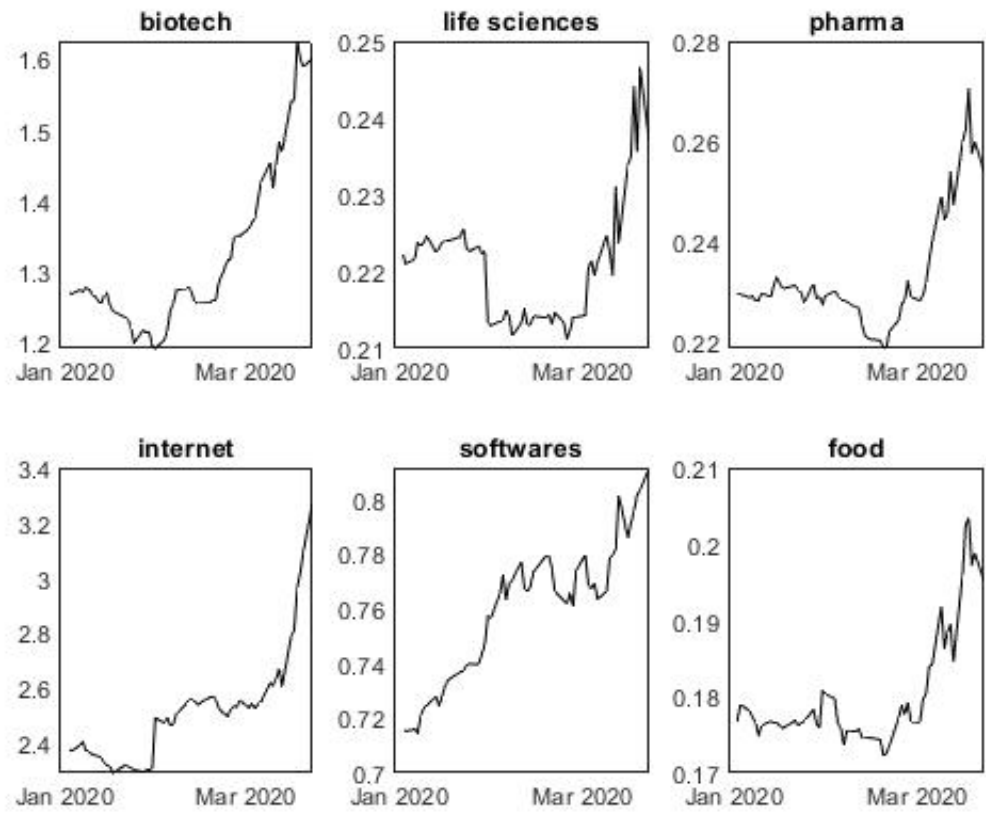

(b) Over-performing sub-indices

Figure 1: Historical values of the S\&P500 sub-indices, at the industry level relative to global S\&P500 from January 1st, 2020 to April 1st, 2020. Source : The Financial Times. 


\begin{tabular}{cccc} 
STOCK & SUB-INDUSTRY & YTD & PUT YTD \\
\hline UNIB-RODAM-WES & Real Estate & $-64.1 \%$ & $807.92 \%$ \\
RENAULT & Automobiles & $-58.4 \%$ & $252.25 \%$ \\
SOCIETE GENERALE & Bank & $-57.2 \%$ & $152.61 \%$ \\
AIRBUS & Aerospace & $-57.0 \%$ & $164.47 \%$ \\
BNP PARIBAS & Bank & $-45.5 \%$ & $116.70 \%$ \\
ACCOR & Hotels & $-45.0 \%$ & $220.33 \%$ \\
CREDIT AGRICOLE & Bank & $-43.8 \%$ & $118.29 \%$ \\
SAFRAN & Aerospace & $-41.1 \%$ & $170.40 \%$ \\
SODEXO & Restaurants & $-38.0 \%$ & $538.70 \%$ \\
PEUGEOT & Automobiles & $-37.0 \%$ & $122.60 \%$ \\
AXA & Insurance & $-35.4 \%$ & $157.20 \%$ \\
PUBLICIS GROUPE & Media Agency & $-35.0 \%$ & $192.40 \%$
\end{tabular}

Table A: Under-performing stocks with their activity sectors, their yields measured between January 1st, and April 1st 2020 and their associated put yields measured over the same time period. The put yields reported are averages of all warrant puts traded during the first quarter of 2020.

\begin{tabular}{cccc} 
STOCK & SUB-INDUSTRY & YTD & CALL YTD \\
\hline HERMES & Clothing & $2.0 \%$ & $10.40 \%$ \\
SANOFI & Pharmaceutical & $-0.1 \%$ & $44.90 \%$ \\
STMICRO & Semi-conductors & $-2.5 \%$ & $2.80 \%$ \\
L'OREAL & Cosmetics & $-4.0 \%$ & $-28 \%$ \\
DASSAULT SYSTEMES & Software & $-4.2 \%$ & $37.90 \%$ \\
AIR LIQUIDE & Chemicals & $-5.0 \%$ & $-7.50 \%$ \\
ATOS & Computer services & $-11.0 \%$ & $44.20 \%$ \\
CARREFOUR & Food retailer & $-11.1 \%$ & $-41.90 \%$ \\
SCHNEIDER ELECTRIC & Electrical components & $-12.1 \%$ & $0.30 \%$ \\
DANONE & Food products & $-13.3 \%$ & $-46.40 \%$ \\
PERNOD RICARD & Distiller and vintner & $-14.2 \%$ & $-27.50 \%$ \\
LVMH & Clothing & $-15.0 \%$ & $-14.00 \%$
\end{tabular}

Table B: Over-performing stocks with their activity sectors, their yields measured between January 1st, and April 1st 2020 and their associated call yields measured over the same time period. The call yields reported are averages of all warrant calls traded during the first quarter of 2020.

The remainder of the paper exploits this heterogeneity to build a corporate insurance scheme against pandemic risks. It is organized as follows. Section 2 develops a conceptual framework that shows how corporate pandemic insurance can be based on a self-funding mechanism, by building on the heterogeneity of sectoral reactions to a pandemic event. We start with a one-period model of an economy, where two stocks are traded, differing according to how their returns react to the occurrence of a pandemic. Type 2 stocks are struck with 
full force by the pandemic event, with a strong decline in their return, should a pandemic occur, while type 1 stocks are less affected and may even take advantage of the pandemic. A risk-averse firm seeks protection against the consequences of a pandemic on its cashflows. This is done by contributing to an insurance fund, managed either directly by the firm itself, or, more realistically, by a mutual or stock insurer acting on behalf of the firm. This insurance fund portfolio, formally analogous to a unit-linked fund, includes a riskless asset (or the issuance of riskless debt), and long or short positions in stocks 1 and 2. An optimal portfolio maximizes the expected utility of the firm's cashflow. Since the firm is risk-averse, this means covering the pandemic risk faced by the firm, while hedging the non-pandemic risks that affect the stock returns. As we will see, the optimal financial investment strategy consists in going long on stock 1 and short on stock 2, so as to obtain benefits from their opposite reaction to pandemic events, while hedging the bearish and bullish non-pandemic episodes affecting the stock market. This results in total or partial coverage of the pandemic and non-pandemic risks, according to whether or not stock returns include a risk premium. In other words, the risk premium required by representative investors in the stock market play a role similar to loading in usual insurance models: they make the cost of transferring risks greater, which affects the optimal level of coverage. Furthermore, in a classical way, the holding of riskless asset (akin to liquid reserves) or the issuance of riskless debt, should equalize the marginal productivity of the firm's capital and the risk-free rate of interest.

Long-short is a widespread strategy among hedge funds: by going long in stocks which have the potential to appreciate, and simultaneously going short in stocks expected to decline in value, hedge fund managers aim at making a profit, while being immunized against the market risk, and without incurring stock delivery costs. This strategy should be adapted, but its underlying logic remains valid, when it is a question of designing an insurance coverage against pandemics, and no more of taking advantage of market mispricing: going short or long in stocks, according to whether or not they are expected to suffer strongly from a pandemic event provides the required coverage, while hedging the nonpandemic risks. Although the long-short strategy is very usual among hedge funds, they are not without disadvantages in terms of transaction costs induced by margin calls, and risk exposure when long and short position do not exactly match. This may justify using put option rather than short positions, and call options rather than long positions. We show that the state-contingent payoff of the insurance fund can be replicated through a portfolio of call options on stock 1 and put options on stock 2, without incurring the disadvantages of the long-short strategy. We conclude Section 2 by extending our analysis to a multiperiod model, in which the firm can transfer funds from period to period, with qualitatively unchanged conclusions.

Section 3 is devoted to numerical simulations of a pandemic insurance fund, using data from the French stock exchange. We first conduct a backtest, in which we assess the insurance strategy described above, over a period of twelve years. Starting from January 2009, an insured firm is assumed to contribute $€ 20,000$ each year to purchase put and call options on the stocks listed in Tables 
$\mathrm{A}$ and $\mathrm{B}$ respectively. At the beginning of each year, the firm purchases put and call options with a maturity of two year. At the end of each year, these options are sold and new ones are purchased. This strategy allows the firm to build a fund that can be liquidated if a pandemic disrupts its activities. We find that a liquidation of the option portfolio on April 1st, in the midst of the COVID-19 crisis, would have delivered a $€ 868,690$ pay-out, hence alleviating the cost of business disruptions. We then simulate future price paths for the stocks listed in Tables $\mathrm{A}$ and $\mathrm{B}$ This prospective exercise results in a distribution of potential payoffs should a crisis, similar to the one of 2020, occur in the future. We find that a firm contributing twelve years, starting from April 1st, 2020 could expect a payoff of $€ 664,780$ euros, should such a crisis occur in 2013.

Finally, Section 4 concludes and Section 5 is an Appendix containing the proofs of the theoretical sections.

\section{The model}

\section{$2.1 \quad$ One-period setting 6}

We analyze the financial choices of a firm facing a pandemic risk, in a one-period model, starting at time $t=0$ and ending at $t=1$. The firm owns initial assets, including productive assets and financial reserves, with total value $A$. A part $I$ of the financial reserves available at $t=0$ is kept as financial assets from $t=0$ to $t=1$, and the remainder is invested as additional productive assets. Hence, the firm has productive assets $K=A-I$ during the current period. In the absence of a pandemic, these productive assets provide cashflows $f(K)$, with $f^{\prime}>0, f^{\prime \prime} \leq 0$, available at $t=1$.

The firm's environment is characterized by two types of uncertainty. Firstly, a pandemic occurs with probability $\pi \in(0,1)$. Secondly, in the absence of pandemic, stock markets are bullish or bearish, with probability $\alpha_{u}$ and $\alpha_{d}$, respectively, with $\alpha_{u}+\alpha_{d}=1$. Thus, there are three states $s \in\{u, d, p\}$, where $u$ (up) and $d$ (down) are the two non-pandemic states (with bullish and bearish market, respectively) and $p$ is the pandemic state, with probability $\alpha_{u}(1-\pi), \alpha_{d}(1-\pi)$ and $\pi$, respectively.

Three securities, indexed by $i \in\{0,1,2\}$, are traded in the financial market, and may be held as reserves by the firm: security $i=0$ is risk-free debt, with interest rate $r_{f}$, and $i=1$ and 2 are two types of stocks. These two stocks are similarly affected by the ups and downs of the business cycle in the nonpandemic states. In the absence of pandemic, the expected return of stock $i$ is denoted $R_{i}$, with returns $R_{i}+h$ and $R_{i}-h^{\prime}$ in states $u$ and $d$, respectively, with $\alpha_{u} h=\alpha_{d} h^{\prime}$. Stocks $i=1$ and $i=2$ differ in their reaction to the occurence of a pandemic: stock 1 is a defensive asset, while stock 2 is severely affected should a pandemic occur: their returns in state $p$ are $R_{1}+H$ and $R_{2}-H^{\prime}$, respectively. We assume $H^{\prime}>h^{\prime}$ and $H+H^{\prime}>0$. Condition $H^{\prime}>h^{\prime}$ reflects the fact

\footnotetext{
${ }^{6}$ Section 5.3 in the Appendix presents an extended version of this model, with arbitrary numbers of assets and states
} 
that stock 2 is severely affected by the pandemic. As regards stock $1, H$ may be positive or negative: the assumption $H>-H^{\prime}$ simply means that stock 1 reacts better than stock 2 to the occurence of a pandemic. We have $R_{2}>R_{1}$ because the higher expected return of stock 2 in the no-pandemic states compensates its stronger downward reaction should a pandemic occur. Overall, the returns of the three assets are summarized in Table C.

\begin{tabular}{|c|ccc|}
\hline$s \backslash i$ & 0 & 1 & 2 \\
\hline$u$ & $r_{f}$ & $R_{1}+h$ & $R_{2}+h$ \\
$d$ & $r_{f}$ & $R_{1}-h^{\prime}$ & $R_{2}-h^{\prime}$ \\
$p$ & $r_{f}$ & $R_{1}+H$ & $R_{2}-H^{\prime}$ \\
\hline
\end{tabular}

Table C: Return of securities

One easily checks that the matrix of security returns is of rank 3 , and thus financial markets are complete. In particular, for each state $s$, an Arrow-Debreu security (i.e., a security that pays one unit of numeraire in state $s$, and zero otherwise) can be obtained through a portfolio of available assets.

\subsection{Covering pandemic losses}

We view the firm as a small or medium-sized enterprise, whose business is not significantly correlated with the ups and downs of the stock market, except when a pandemic is at the origin of a business interruption, causing losses in an amount equal to $L$. Thus, the final cashflow derived from productive assets is $f(K)$ in states $u$ and $d$, and $f(K)-L$ in state $p$. The firm is supposed to be riskaverse with respect to its final net cashflow including the payoff of its financial holdings (in short, its cashflow), either because of the investment crowding-out mechanism analyzed by Froot-Scharfstein and Stein (1993), or because its owner has a non-diversified wealth, or because a decrease in cashflow exacerbates the risk of bankruptcy in the future.

The firm makes its financial choices so as to maximize the expected utility of its cashflows

$$
\sum_{s \in\{u, d, p\}} \pi_{s} u\left(w_{s}\right),
$$

where $w_{s}$ is the firm's cashflow in state $s$ (more precisely defined below), $\pi_{s}$ is the probability of state $s$ (i.e. $\pi_{u}=\alpha_{u}(1-\pi), \pi_{d}=\alpha_{d}(1-\pi)$ and $\pi_{p}=\pi$ ), and $u($.$) is a von Neumann-Morgenstern utility function that represents the firm's$ risk aversion, with $u^{\prime}>0$ and $u^{\prime \prime}<0$.

The firm allocates a part $x_{i}$ of its reserves to security $i$ with

$$
\sum_{i \in\{0,1,2\}} x_{i}=I
$$

The firm's cashflow is the sum of the casflow $f(K)=f(A-I)$ derived from its productive assets, cut by the loss $L$ in the case of a pandemic, and of the payoff 
of its financial holdings, which gives

$$
\begin{aligned}
& w_{s}=f\left(A-\sum_{i \in\{0,1,2]} x_{i}\right)+\sum_{i \in\{0,1,2]}\left(1+r_{s i}\right) x_{i} \text { if } s \in\{u, d\}, \\
& w_{p}=f\left(A-\sum_{i \in\{0,1,2]} x_{i}\right)+\sum_{i \in\{0,1,2]}\left(1+r_{p i}\right) x_{i}-L,
\end{aligned}
$$

where $r_{s i}$ is the return of security $i$ in state $s$, as decribed in Table 1 . The firm's optimal financial policy is obtained by maximizing the expected utility of cashflows with respect to $x_{0}, x_{1}$ and $x_{2}$. Furthermore, and more realistically, the financial positions of the firm may be intermediated by a financial institution, such as an insurance company, offering self-funded hedging mechanisms.

Since financial markets are complete, the price of Arrow-Debreu securities (or state prices) $q_{u}, q_{d}$ and $q_{p}$ can be recovered from the matrix of asset returns. When there are risk-neutral investors in the financial markets, the expected return of stocks are equal to the risk-free interest rate, i.e.

$$
r_{f}=R_{1}+\pi H=R_{2}-\pi H^{\prime}
$$

and in that case, the vector of state prices is proportional to the state probability vector. More realistically, we may assume that the return on stocks include a risk premium because of investors' risk aversion, a case in which we have

$$
r_{f}<R_{1}+\pi H \text { and } r_{f}<R_{2}-\pi H^{\prime}
$$

States $u, d$ and $p$ correspond to various degrees of macroeconomic prosperity, state $p$ corresponding to a most severe economic downturn. Lemma 1 provides a sufficient condition on the security returns for this to be reflected in a simple hierarchy of probability-weighted state prices.

Lemma 1 When (3) holds, i.e. there are risk-neutral investors, the ArrowDebreu security prices are such that

$$
\frac{1}{1+r_{f}}=\frac{q_{u}}{\alpha_{u}(1-\pi)}=\frac{q_{d}}{\alpha_{d}(1-\pi)}=\frac{q_{p}}{\pi} .
$$

When (4) holds, i.e. all investors are risk-averse, then we have

$$
\frac{q_{u}}{\alpha_{u}(1-\pi)}<\frac{1}{1+r_{f}}<\frac{q_{d}}{\alpha_{d}(1-\pi)} .
$$

If in addition we have

$$
\frac{R_{2}-\pi H^{\prime}-r_{f}}{R_{1}+\pi H-r_{f}}>\frac{h+\pi H^{\prime}}{h-\pi H}
$$

then

$$
\frac{q_{d}}{\alpha_{d}(1-\pi)}<\frac{q_{p}}{\pi} .
$$


Condition (7) means that the risk premium is substantially larger for stock 2 than for stock 1 . This reflects the catastrophic nature of state $p$ in which stock 2 has a very low return $R_{2}-H^{\prime}$ by comparison with its no-pandemic expected return $R_{2}$, while the relative performance is better for stock 1 . In what follows, we refer to (5), and (6)-(8) as the investors' risk neutrality and risk aversion cases, respectively, in relationship with the attitude toward risk of a representative investor who may require risk premium to hold the securities in its portfolio. As assumed, the firm under consideration is risk averse.

The firm chooses its portfolio $\left(x_{0}, x_{1}, x_{2}\right)$ of assets 0,1 and 2 (or, equivalently, it chooses a portfolio of Arrow-Debreu Securities) in order to maximize its expected utility. Let $y_{s}$ denote the quantity of type $s$ Arrow-Debreu security purchased by the firm, with $s \in\{u, d, p\}$, with

$$
\begin{aligned}
& w_{s}=f\left(A-q_{u} y_{u}-q_{d} y_{d}-q_{p} y_{p}\right)+y_{s} \text { if } s \in\{u, d\}, \\
& w_{p}=f\left(A-q_{u} y_{u}-q_{d} y_{d}-q_{p} y_{p}\right)+y_{p}-L .
\end{aligned}
$$

The firm chooses $y_{u}, y_{d}$ and $y_{p}$ in order to maximize its expected utility $\sum_{s \in\{u, d, p\}} \pi_{s} u\left(w_{s}\right)$, and its portfolio $\left(x_{0}, x_{1}, x_{2}\right)$ can then be deduced from the data on asset returns.

Proposition 1 If investors are risk neutral, then

$$
w_{u}=w_{d}=w_{p},
$$

and the firm's portfolio is such that

$$
\begin{aligned}
& x_{0}=A-K, \\
& x_{1}=-x_{2}=\frac{L}{H+H^{\prime}},
\end{aligned}
$$

If investors are risk averse, then

$$
w_{u}>w_{d}>w_{p},
$$

and the firm's portfolio is such that

$$
\begin{aligned}
& x_{0}<A-K, \\
& x_{1}+x_{2}=\frac{w_{u}-w_{d}}{h+h^{\prime}}>0, \\
& -x_{2}<\frac{L}{H+H^{\prime}} .
\end{aligned}
$$

In both cases, we have $K=K^{*}$ given by

$$
f^{\prime}\left(K^{*}\right)=1+r_{f} .
$$

Hence, when investors are risk-neutral, an optimal financial strategy of the firm consists of going long on stock 1 and short on stock 2, for exactly the same amount, i.e. $x_{1}+x_{2}=0$. In more concrete terms, at $t=0$ the firm 
sells stock 2 after borrowing it on the spot market and uses the proceeds of this sale to purchase stock 1 . Hence, no net disbursement is required for these stock market operations. At $t=1$, the firm purchases stock 2 and cancels its short position, Because of the zero aggregate net position of the firm's stock portfolio from $t=0$ to $t=1$, in state $u$ the high return from the long position on stock 1 exactly compensates the low return from the short position on stock 2 , and vice versa in state $d$. Hence, these opposite positions allow the firm to perfectly hedge its market exposure in the non-pandemic states $u$ and $d$, with an aggregate return equal to the risk-less interest rate $r_{f}$. The size of these long and short positions is chosen in order to perfectly cover the firm's loss $L$ in the case of a pandemic, which will be the case when (13) holds. The firm holds reserves or borrows money at the risk-less interest rate $r_{f}$, according to whether $A$ is larger or lower than $K^{*}$, respectively. To put it simply, when there are risk-neutral investors, the firm can use stock market operations to fully cover the losses caused by a pandemic, while perfectly hedging its exposures to nonpandemic market fluctuations, and ultimately its cash-flows are independent from the state that may occur.

When investors are risk-averse, the return on stocks includes risk premiums and the higher these returns, the higher the probability-weighted state prices. More explicitly, from (6) and (8), substituting wealth from state $u$ to state $d$ can be done at rate $q_{d} / q_{u}$ which is larger than the odds ratio $\alpha_{d} / \alpha_{u}$, and similarly $q_{p} / q_{d}$ is larger than $\pi / \alpha_{d}(1-\pi)$. These distortions between state-price ratios and odds ratios make the hedging of pandemic and non-pandemic risks more costly, hence the partial coverage of cashflows reflected in inequalities (14): the firm is better off in state $u$ than in state $d$, the pandemic state $p$ being the worse. In the case of risk-neutral investors, it was optimal to hedge the non-pandemic risk (i.e., to substitute wealth in state $d$ to wealth in state $u$ ) by going long on stock 1 and short on stock 2 , with equal positions in absolute value. When the aggregate firm's position in the stock market is long, i.e., when $x_{1}+x_{2}>0$, the firm's financial performances are higher in state $u$ than in state $d$, which corresponds to the partial hedging of non-pandemic financial risk. As expressed by (16), the aggregate position $x_{1}+x_{2}$ is proportional to $w_{u}-w_{d}$, which depends on the firm's degree of risk aversion. Conditions (13) and (17) show that partial coverage of the pandemic risk goes through a short position on stock 2 which is smaller than in the risk neutral case.

Finally, in both cases, for an optimal level of productive capital $K^{*}$, the discounted marginal productivity of capital $f^{\prime}\left(K^{*}\right) /\left(1+r_{f}\right)$ should equal 1 , which corresponds to a standard corporate value maximization rule.

Remark 1 Sofar we have assumed that financial assets are held by the firm itself. It is more realistic, particularly for a small or medium-sized firm, to restrict its financial operations to the holding of a remunerated bank account if $x_{0}>0$ and to the issuance of debt if $x_{0}<0$, the riskless interest rate $r_{f}$ applying in both cases, and to relate the return from stocks to contractual links with a financial institution. In this interpretation, the return on stocks 1 and 2 correspond to the payout of a self-funded pandemic insurance scheme managed by an 
insurance company or a bank. At $t=0$, the firm (or its owner, in the case of a single owner) contributes an amount $x_{1}+x_{2}$ to the insurance scheme, and has the right to decide how this financial investment gets allocated between stocks 1 and 2 . The firm receives the proceeds of the insurance scheme at $t=1$. The objective of this scheme is to provide coverage against the risks that affect the firm's cashflow, in a setting where no risk mutualization is feasible. This insurance dimension is particularly obvious in the case of risk-neutral investors: the scheme allows the firm's owner to perfectly hedge its non-pandemic risks (i.e., the ups and downs of financial markets), and also to fully cover the firm's loss, should a pandemic occur. This insurance feature remains true when investors are risk-averse, but the scheme only provides partial hedging of non-pandemic risks and partial coverage of the losses that may result from a pandemic.

Remark 2 We have assumed that the returns of stocks 1 and 2 have the same standard deviation $\left(\alpha_{u} h^{2}+\alpha_{d} h^{\prime 2}\right)^{1 / 2}$ in the non-pandemic states $u$ and $d$. This assumption was made to simplify calculations, but our qualitative conclusions would remain unchanged in a more general setting, were the variability of returns may differ between between stocks 1 and 2. Table $D$ corresponds to such a more general setting, in which stocks 1 and 2 may react more or less to the bullish or bearish state of the market.

\begin{tabular}{|c|ccc|}
\hline$s \backslash i$ & 0 & 1 & 2 \\
\hline$u$ & $r_{f}$ & $R_{1}+h_{1}$ & $R_{2}+h_{2}$ \\
$d$ & $r_{f}$ & $R_{1}-h_{1}^{\prime}$ & $R_{2}-h_{2}^{\prime}$ \\
$p$ & $r_{f}$ & $R_{1}+H$ & $R_{2}-H^{\prime}$ \\
\hline
\end{tabular}

Table D: Case where the non-pandemic volatility of stock returns differ between stocks

We assume $\alpha_{u} h_{i}=\alpha_{d} h_{i}^{\prime}$ for $i=1,2$, so that $R_{i}$ still denotes the expected return of stock $i$ in the non-pandemic states, and stock 1 is more volatile than stock 2 if $h_{1}>h_{2}$, and vice versa. When investors are risk neutral, it is still possible to hedge the market risk in the non-pandemic states while covering the loss $L$ in the case of a pandemic, by choosing $x_{1}$ and $x_{2}$ such that

$$
\frac{x_{1}}{h_{1}}=\frac{x_{2}}{h_{2}}=\frac{L}{h_{1} H+h_{2} H^{\prime}},
$$

which is an extension of condition (13) to this broader setting. Our conclusions when investors are risk-averse could be adapted in a similar way.

The coverage mechanism at work is to have a portfolio of long and short positions in the stock market in order to hedge the non-pandemic risk and simultaneously to compensate the firm for the loss incurred in the case of a pandemic. To do so, the firm (or the insurance company managing the self-funded insurance scheme) goes long on stock 1 and short on stock 2. Alternatively, an adequate portfolio of call and put options purchased at $t=0$ with maturity date 
$t=1$ may allow the firm to hedge its risks, in the same way as if it were going long and short on the stocks themselves. For illustration purposes, consider call options on stocks 1 and put options on stock 2 , with strike price $1+R_{1}$ and $1+R_{2}$, respectively, the value of each stock being equal to 1 at $t=0$. Hence, for each option the strike price is equal to the expected payoff of the stock in the non-pandemic states. We consider the case where $H>0$ so that the call option on stock 1 is in the money in states $u$ and $p$ (with payoffs $h$ and $H$, respectively), while the put option on stock 2 is in the money in states $d$ and $p$ (with payoffs $h^{\prime}$ and $H^{\prime}$, respectively). Let $q_{c 1}$ and $q_{p 2}$ be the price of the call and put options, on stocks 1 and 2, respectively. For simplicity, consider the case where investors are risk-neutral, and thus the price of securities is equal to the discounted value of their expected payoff, which gives

$$
\begin{aligned}
& q_{c 1}=\frac{\alpha_{u} h(1-\pi)+\pi H}{1+r_{f}}, \\
& q_{p 2}=\frac{\alpha_{d} h^{\prime}(1-\pi)+\pi H^{\prime}}{1+r_{f}} .
\end{aligned}
$$

Let $z_{c 1}$ and $z_{p 2}$ be the value of calls and puts (on stocks 1 and 2, respectively) purchased at $t=0$, and $z_{c 1} / q_{c 1}$ and $z_{p 2} / q_{p 2}$ the corresponding numbers of op-

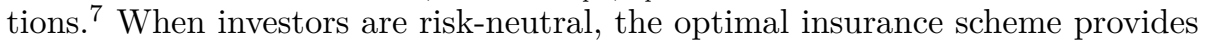
perfect hedging of non-pandemic risks and full coverage of the loss in the case of a pandemic, which gives

$$
y=y_{u}=y_{d}=y_{p}-L .
$$

These state-dependent financial cashflows are associated with a portfolio $\left(x_{0}, z_{c 1}, z_{c 2}\right)$ if the following conditions are satisfied:

$$
\begin{aligned}
& x_{0}\left(1+r_{f}\right)+z_{c 1} \frac{h}{q_{c 1}}=y, \\
& x_{0}\left(1+r_{f}\right)+z_{p 2} \frac{h^{\prime}}{q_{p 2}}=y, \\
& x_{0}\left(1+r_{f}\right)+z_{c 1} \frac{H}{q_{c 1}}+z_{p 2} \frac{H^{\prime}}{q_{p 2}}=y+L .
\end{aligned}
$$

Solving (20)-(22) for $x_{0}, z_{c 1}$ and $z_{p 2}$ yields

$$
\begin{aligned}
& x_{0}=\frac{y}{1+r_{f}}-\frac{h h^{\prime} L}{H h^{\prime}+h\left(H^{\prime}-h^{\prime}\right)} \\
& \frac{z_{c 1}}{q_{c 1}}=\frac{h^{\prime} L}{H h^{\prime}+h\left(H^{\prime}-h^{\prime}\right)}>0, \\
& \frac{z_{p 2}}{q_{p 2}}=\frac{h L}{H h^{\prime}+h\left(H^{\prime}-h^{\prime}\right)}>0 .
\end{aligned}
$$

\footnotetext{
${ }^{7} z_{c 1}$ and $z_{p 2}$ are positive or negative, according to whether the firm goes long or short in each option market.
} 
Hence following a long-short portfolio management strategy and holding a portfolio of call and put options are two ways to reach the same goal, i.e., covering simultaneously the non-pandemic market risks and the loss that may result from a pandemic. Most interestingly, it turns out that these two financial strategies, usually restricted to pure portfolio management with performance benchmarking, are relevant when it comes to designing the coverage strategy of a firm facing a risk with a systemic dimension, i.e., whose occurrence coincides with a non-diversifiable shock on the stock market. Portfolio management and corporate insurance are converging here, in the search for an optimal pandemic insurance scheme.

Nevertheless, behind this methodological alignment, there are important practical differences between the two strategies. Short stock positions are typically only given to accredited investors (which is in accordance with our interpretation of intermediation through an insurance company or a bank), who are usually required to place a margin deposit or collateral with the broker in exchange for the loaned shares. In practice, this creates non-negligible transaction costs and thereby reduces the attractiveness of such self-funded insurance schemes for small or medium-sized firms, with limited financial resources. The option-based financial strategy would exonerate these firms from such transaction costs, by shifting the margin calls to a much larger set of financial investors who act as counter-parts in option markets. Furthermore, short positions on stock 2 expose investors to potentially unlimited risk of loss if, for any reason, this stock performs better than expected, while, with the put options, the maximum loss is restricted to the price paid for the puts. Finally, borrowing stock 2 to short it may entail transaction costs that have been ignored, as well as interest payable on the margin account, while put options only require an up-front cost to purchase the puts, but no other ongoing expenses. For all these reasons, although long-short and options are two ways to reach the same goal, options may be considered as a cheaper and less risky strategy.

\section{$2.3 \quad$ Multi-period setting}

Let us extend our results to an infinite horizon model, where time periods are indexed by $t=0,1 \ldots$, and the firm can transfer financial resources across time. The notations are adapted from the one-period setting as follows. At each period $t$, the total value of the firm's initial assets is equal to $A_{t}$, allocated between productive assets $K_{t}$ (including investment made at the beginning of period $t$ ) and financial reserves $A_{t}-K_{t}$. Productive assets provide cashflows $f\left(K_{t}\right)$, with $f^{\prime}>0, f^{\prime \prime} \leq 0$, available at the end of period $t$. We still assume that three states $s \in\{u, d, p\}$ may occur at each period $t$, with probability $\pi_{s}$ equal to $\alpha_{u}(1-\pi), \alpha_{d}(1-\pi)$ and $\pi$, respectively, and that the firm incurs loss $L$ in the pandemic state $p$. The probability distributions of states are assumed to be independent between periods. Financial reserves are allocated between securities $i=0,1$ and 2 with return $r_{s i}$ in state $s$ as specified in Table 1 . We denote $x_{t i}$ the value of security $i$ held by the firm at period $t$. Since the firm's assets are allocated between productive and financial assets at the beginning of 
each period, we have

$$
A_{t}=K_{t}+\sum_{i \in\{0,1,2\}} x_{t i}
$$

The total cashflows come from productive and financial assets, and they are allocated either to the owner's consumption (through the distribution of dividend) or to corporate investment, i.e. to the increase in the value of the firm's assets. This allocation of cashflows depends on the state prevailing during the period. Let $c_{s t}$ denote the consumption level in state $s$ at period $t$, and let $A_{t+1, s}$ be the value of the firm's assets at the beginning of period $t+1$ when state $s$ prevails at period $t$, hence with total investment $A_{t+1, s}-A_{t}$. The cashflows coming from productive and financial assets, possibly reduced by loss $L$, are equal to the sum of consumption and investment, and thus we have

$$
\begin{aligned}
c_{t s}+A_{t+1, s}-A_{t} & =f\left(K_{t}\right)+\sum_{i \in\{0,1,2\}}\left(1+r_{s i}\right) x_{t i} \text { if } s \in\{u, d\}, \\
c_{t p}+A_{t+1, p}-A_{t} & =f\left(K_{t}\right)+\sum_{i \in\{0,1,2\}}\left(1+r_{p i}\right) x_{t i}-L .
\end{aligned}
$$

The firm chooses its portfolio of financial assets $\left(x_{t 0}, x_{t 1}, x_{t 2}\right)$ and its statecontingent investment level $A_{t+1, s}-A_{t}$, in order to maximize the discounted sum of consumption expected utility

$$
\sum_{t=0}^{\infty} \delta^{t} \sum_{s_{t} \in\{u, d, p\}} \pi_{s_{t}} u\left(c_{t s_{t}}\right),
$$

where $\delta$ is the discount factor, such that $\delta<1$, and $s_{t}$ is the state at period $t$.

The intertemporal strategy of the firm is characterized by functions $A_{t}\left(h_{t}\right)$ and $x_{t i}\left(h_{t}\right)$ for all $t \geq 0$ and all $i \in\{0,1,2\}$, where $h_{t}=\left(s_{0}, s_{1}, \ldots, s_{t-1}\right) \in$ $H_{t} \equiv\{u, d, p\}^{t}$ denotes the sequence of states from period 0 to period $t-1$ if $t \geq 1$ and $h_{0} \in \varnothing$. Let $\Pi_{t}\left(h_{t}\right)$ be the probability of sequence $h_{t}$ when $t \geq 1$, with $\sum_{h_{t} \in H_{t}} \Pi_{t}\left(h_{t}\right)=1$. For notational consistency, we denote $\Pi_{0}\left(h_{0}\right)=1$. In words, $A_{t}\left(h_{t}\right)$ is the value of the firm's assets at the beginning of period $t$, with the constraint $A_{0}\left(h_{0}\right) \equiv A_{0}$ imposed by the value of initial assets, and thus $A_{t+1}\left(h_{t+1}\right)-A_{t}\left(h_{t}\right)$ is its investment at period $t$, while $\left(x_{t 0}\left(h_{t}\right), x_{t 1}\left(h_{t}\right), x_{t 2}\left(h_{t}\right)\right)$ is its portfolio of financial assets held during period $t$. The firm maximizes its expected utility

$$
\begin{aligned}
& \sum_{t=0}^{\infty} \delta^{t}\left\{\sum _ { h _ { t } \in H _ { t } } \Pi _ { t } ( h _ { t } ) \sum _ { s _ { t } \in \{ u , d , p \} } \pi _ { s _ { t } } u \left(f \left(A_{t}\left(h_{t}\right)-\sum_{i \in\{0,1,2\}} x_{t i}\left(h_{t}\right)\right.\right.\right. \\
& \left.\left.\left.+\sum_{i \in\{0,1,2\}}\left(1+r_{s_{t}}\right) x_{t i}\left(h_{t}\right)+A_{t}\left(h_{t}\right)-A_{t+1}\left(h_{t}, s_{t}\right)-\mathbb{1}\left(s_{t}=p\right) L\right)\right)\right\},
\end{aligned}
$$

with respect to $A_{t}():. H_{t} \rightarrow R_{+}$for all $t \geq 1$ and $x_{t i}():. H_{t} \rightarrow R$ for $i \in\{0,1,2\}$ and all $t \geq 0$. Let $v\left(A_{0}\right)$ be the optimal expected utility level as a function 
of initial assets $A_{0}$, with $v^{\prime}\left(A_{0}\right)>0$ and $v^{\prime \prime}\left(A_{0}\right)<0.8$ At period $t=0$, the firm chooses its portfolio $\left(x_{00}, x_{01}, x_{02}\right)$ and its state-dependent investment level $A_{1}\left(s_{0}\right)-A_{0}$ in order to maximize

$$
\begin{aligned}
& \sum_{s_{0} \in\{u, d, p\}} \pi_{s_{0}}\left[u \left(f\left(A_{0}-\sum_{i \in\{0,1,2\}} x_{0 i}\right)+\sum_{i \in\{0,1,2\}}\left(1+r_{s_{0} i}\right) x_{0 i}\right.\right. \\
& \left.\left.+A_{0}-A_{1}\left(s_{0}\right)-\mathbb{1}\left(s_{t}=p\right) L\right)+\delta v\left(A_{1}\left(s_{0}\right)\right)\right],
\end{aligned}
$$

where the effect of current decisions on the discounted expected utility in next periods goes through the last term $\delta v\left(A_{1}\left(s_{0}\right)\right)$. Conditionally on state $s_{0}$, the future assets $A_{1}\left(s_{0}\right)$ are chosen so as to maximize the discounted expected utility

$$
\begin{aligned}
& u\left(f\left(A_{0}-\sum_{i \in\{0,1,2\}} x_{0 i}\right)+\sum_{i \in\{0,1,2\}}\left(1+r_{s_{0} i}\right) x_{0 i}\right. \\
& \left.\left.+A_{0}-A_{1}\left(s_{0}\right)-\mathbb{1}\left(s_{t}=p\right) L\right)+\delta v\left(A_{1}\left(s_{0}\right)\right)\right] .
\end{aligned}
$$

Hence, the portfolio $\left(x_{00}, x_{01}, x_{02}\right)$ maximizes

$$
\sum_{s_{0} \in\{u, d, p\}} \pi_{s_{0}}\left[\bar{u}\left(f\left(A_{0}-\sum_{i \in\{0,1,2\}} x_{0 i}\right)+\sum_{i \in\{0,1,2\}}\left(1+r_{s_{0} i}\right) x_{0 i}-\mathbb{1}\left(s_{t}=p\right) L\right)\right.
$$

where indirect utility function $\bar{u}($.$) is defined by$

$$
\bar{u}(w) \equiv \max _{A_{1}}\left\{u\left(w+A_{0}-A_{1}\right)+\delta v\left(A_{1}\right)\right\},
$$

with $\bar{u}^{\prime}>0$ and $\bar{u}^{\prime \prime}<09$ Hence, in this multi-period setting, the optimal portfolio is the solution to an optimization problem deduced from the one-period problem by replacing utility function $u$ by the indirect utility function $\bar{u}$. The concavity of function $\bar{u}$ allows us to conclude that the results obtained in the one-period setting are also valid in this multi-period setting, with unchanged qualitative conclusions.

\section{Numerical simulations}

In this section, we conduct simulations that illustrate the functioning of the insurance scheme discussed in the previous sections. This exercise will allow us to assess the coverage made possible by pandemic self-funded insurance, by using data from the French stock exchange. Our perspective will be first retrospective, and then prospective. From a retrospective standpoint, we will

\footnotetext{
${ }^{8}$ Note that the expected utility is a concave function of the parameter $A_{0}$ and of the unknowns $A_{t}\left(h_{t}\right)$ and $x_{t i}\left(h_{t}\right)$, which implies the concavity of the value function $v\left(A_{0}\right)$.

${ }^{9}$ The envelope theorem gives $\bar{u}^{\prime}(w)=u^{\prime}\left(w+A_{0}-A_{1}\right)>0$. Differentiating the first-order optimality conditions yields $d A_{1} / d w=u^{\prime \prime} /\left(\delta v^{\prime \prime}+u^{\prime \prime}\right)$, which implies $\bar{u}^{\prime \prime}(w)=\delta u^{\prime \prime} v^{\prime \prime} /\left(\delta v^{\prime \prime}+\right.$ $\left.u^{\prime \prime}\right)<0$.
} 
ask the question of what amount of coverage would have been available at the outbreak of the COVID-19 crisis, if the insured firm had invested during the previous decade in two option-based funds, with underlyings similar to stocks 1 and 2 of our theoretical model. In a forward-looking perspective, we will simulate the coverage from such a financial investment strategy when the returns of the underlying stocks are random and the next pandemic occurs a decade after the start of the financial investment phase.

\subsection{Backtest}

We first perform a backtest of the following strategy: each year, from January 1st 2009 to January 1st 2020, €20,000 are invested in the insurance scheme composed of two funds. Fund 1 is composed of call options, whose underlyings are the twelve stocks listed in Table $B$, that are expected to resist well to a pandemic shock. Fund 2 is composed of put options on the twelve stocks of Table A that are expected to under-perform the CAC40 in the pandemic state. Each year, the strategy re-balances the two funds values. The symmetry between the funds aims at neutralizing the effect of a potential trend in stock prices since a general price increase benefits the calls and harms the puts while a general price drop benefits the puts at the expense of the calls.

Between 2009 and 2019, the French stock market experienced a $85.8 \%$ increase in the CAC40 index. This marked evolution favours capitalization in fund 1. In contrast, the fund 2 incurs a loss each year. A negative trend over the period would have had the opposite effect. Since it is hard to predict the direction of stock markets, a symmetrical strategy of investment in the two funds may be viewed as a prudent approach 10

The yields of the two funds where computed by reconstituting each year the value of options with the following characteristics : options purchased at the beginning of each year have a maturity of two years and are sold at the end of the year, with a remaining maturity of one year. The strike price is equal to the current price of the underlying asset at the moment of purchase. Option prices were calculated retrospectively using the Black-Scholes formula on the basis of the historical underlying prices and option characteristics 11

At the beginning of each year, the additional $€ 20,000$ contribution is added to the total fund value which is split in two equal parts to finance the purchase of new put and call options. This results in a year-by-year evolution of the

\footnotetext{
${ }^{10}$ In portfolio management, a straddle consisting in simultaneous purchases of call and put options with the same underlying stock, is a way to hedge the uncertainty about the return of this stock. The same logic applies when it comes to hedge the market risk that affects the underlyings of the two funds.

${ }^{11}$ Hence, the procedure we followed consisted in estimating the price of options whose characteristics may be considered as representative of calls and puts traded in the Paris stock exchange. Another approach would have consisted in deriving option prices from the list of actual options listed in the warrant market. We have opted for the first approach for practical reasons, related to data availability, but also because, for each stock listed in the CAC40, there are many put and call options, with various maturities and strike prices, which would have made our analysis untractable.
} 
two funds' values. Results are presented in Table E. The total contribution is equal to $€ 240,000$ on January 1st 2020. With the notable exceptions of 2011 and 2018, the fund invested in put options, i.e., fund 2, yields a negative payoff due to the positive trend of the stock market over the period (except in 2011 and 2018). In contrast, the fund invested in call options, i.e. fund 1, provides positive payoffs that more than compensates the losses of fund 2 most years and helps to increase the overall fund value. At the beginning of year 2020, the fund accumulated a total of $€ 395,005$, re-invested half in calls and half puts, as at the beginning of each year. This portfolio of puts with underlying assets particularly vulnerable to the pandemic shock generates a yield that offsets the limited losses incurred by the calls, whose underlying assets have been chosen to resist the crisis. This results in a total of 868,690 euros available to the firm when the crisis hits, the options being sold on April 1st, 2020. The backtest therefore results in a 628,690 euros excess payoff for the firm. If contributions to the fund were considered as tax-deductible, then the net excess payoff would even be larger, and would reach $€ 664,690$ and $€ 700,690$ when corporate tax rate is $15 \%$ and $30 \%$, respectively.

\section{$3.2 \quad$ Forward-looking analysis}

We now turn to an exercise of forward-looking simulations. Instead of using the historical values of the underlying asset prices, we use the log-normal assumption, on which the Black-Scholes model is built, to simulate a large number of potential future stock prices. In order to remain as neutral as possible, we assume that daily stock returns have a zero expected value, so that prices have a flat trend. The outcome of the insurance strategy (i.e., of financial investments made by the firm at the beginning of each year) is evaluated on each simulated price path. A histogram of potential payoffs is hence constructed, which allows to assess not only the expectation, but the full distribution of the compensation received by the insured firm in the pandemic state.

We assume that the firm starts contributing to the funds on April 1st, 2020. For the purpose of comparability with the backtest exercise conducted above, we assume that the firm makes twelve yearly payments of $€ 20,000$ and that a pandemic crisis, affecting assets in the same proportions as the 2020 crisis, occurs in 2031 12 More specifically, we assume that the crisis starts in August 1st, 2031 and that the funds are liquidated in October 1st 2031 to provide a compensation to the insured firms. The risk-free interest rate is assumed constant at its last value in the data-set (April 1st 2020) and the stock volatilities, also assumed constant, are equal to their historical values ${ }^{13}$ The data-set is composed of daily price fluctuations of the twenty-four stocks listed in Tables $\mathrm{A}$ and $\mathrm{B}$ between January 1st 2007 and April 1st 2020. This allows us to calculate the price of call and put options, strike price being equal to the current price of underlyings.

\footnotetext{
${ }^{12}$ For simplicity, we assume that each stock incurs the exact same percentage loss than between February 1st, 2020 and April 1st, 2020.

13 Time-varying interest rates and volatility could be acknowledged easily through OrnsteinUhlenbeck and GARCH processes for example.
} 


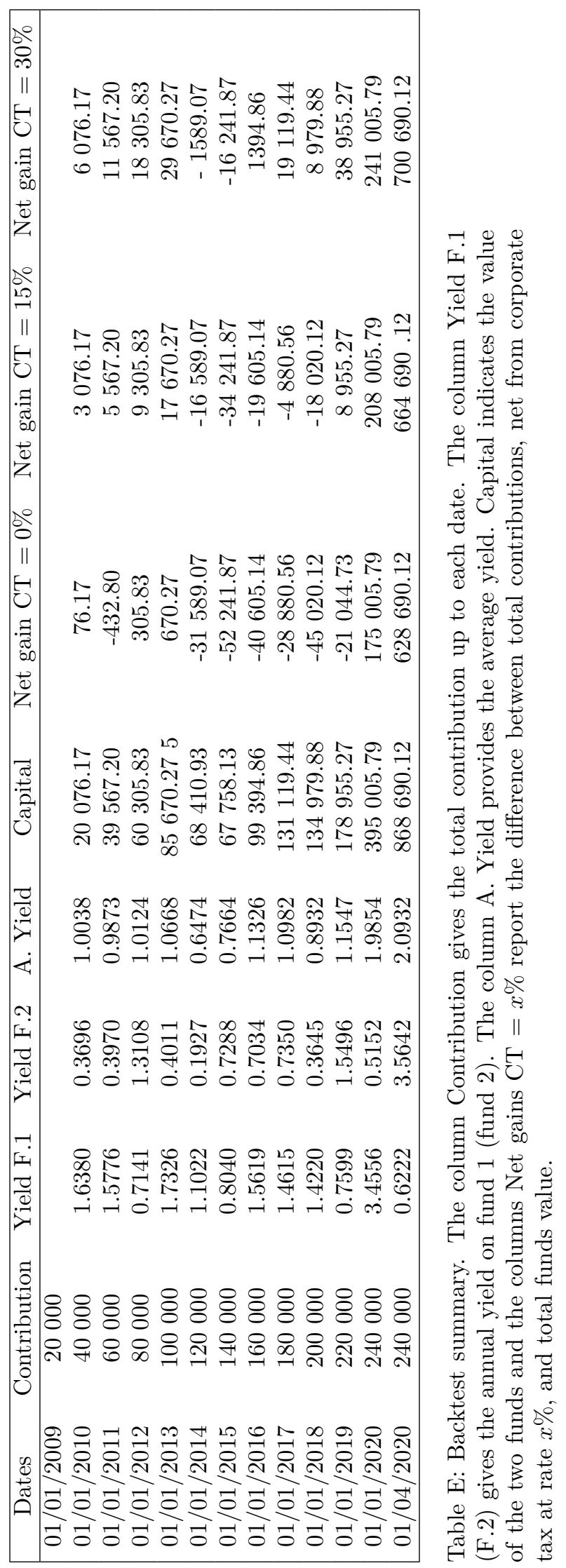




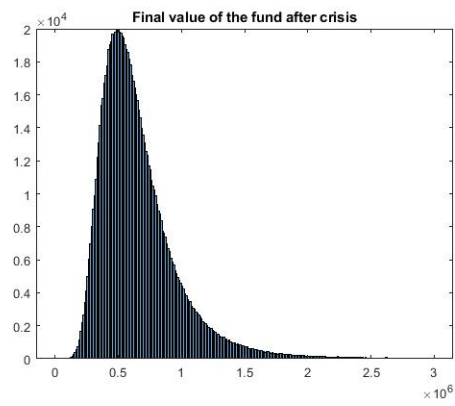

(a) Strike prices equal to underlying prices. Mean value : 664780 , median : 590 570, 5th percentile : 304 830, 1st percentile : 231240 .

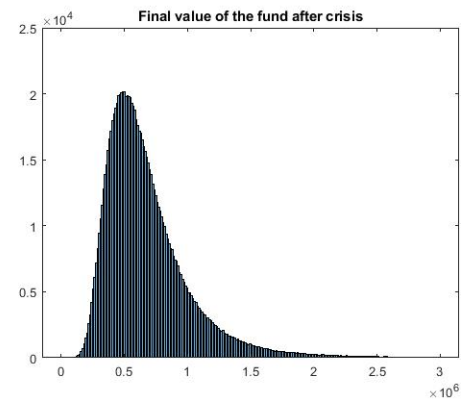

(b) Strike prices of the put lower than underlying prices. Mean value : 689 970, median : 606300,5 th percentile : 304300 , 1st percentile : 229400.

Figure 2: Distributions of the total fund's value

Figure 2a displays the histogram of the 1 million random draws simulated. The average value of the two funds across draws is equal to $€ 664,780$ euros while the median is $€ 590,570$ euros. $95 \%$ of the simulated paths deliver a final value above $€ 304,830$ euros and $99 \%$ of them provide a value higher than $€ 231,240$ euros. This has to be compared with the cumulative investment cost of 240,000, reduced to 204,000 and 168,000 if the firm's contributions are tax-deductible, with corporate tax rate of $15 \%$ and $30 \%$, respectively.

It is possible to alter the distribution of the total fund's value by changing the characteristics of the traded option. Figure $2 \mathrm{~b}$ for example, represents the final distribution of the pandemic insurance scheme under the same assumptions as represented in Figure 2a. except for the value of the put strike prices. Instead of selecting put options with strike prices equal to the current value of the underlying, it is assumed that the insured firm buys and sells out-of-the-money options with a strike price equal to $70 \%$ of the underlying asset's current price. Since a lower strike price increases leverage, the resulting distribution is more spread-out. It mean and median are both higher, at $€ 689,970$ and $€ 606,300$ euros respectively, but its first and fifth percentiles are smaller, at $€ 304,300$ and $€ 229,400$ euros, respectively.

\section{Conclusion}

In many countries, including the U.S. and in Europe, the COVID-19 crisis has highlighted inadequate preparation for pandemics, and the current state of business interruption insurance is illustrative of this deficiency. Pandemic risk displays features that are deeply different from those of other insurance risks: it 
affects simultaneously a large fraction of businesses, which makes risk mutualization unfeasible, and in addition, it is systemic in nature, since it goes along with a worldwide severe economic downturn. As result, in responding to the demand for corporate pandemic insurance, innovation is required. We cannot merely pour new wine into old bottles!

Having recognized that pandemics do not affect all sectors of the real economy in the same way, we have analyzed how corporate insurance could be built through a capitalization strategy. This consists either in following a long-short strategy in the stock market, or in investing in stock options, or of course in a mixture of the two. The logic of this strategy is to take advantage of the downturn of the stocks that are most exposed to pandemics, and, if possible, of the stimulus given to specific sectors, in order to generate substantial gains in the case of a pandemic, while hedging the risks associated with the bearish or bullish nature of the stock market in non-pandemic states. Simulations using data from the French stock market, either retrospectively or prospectively, have illustrated the potential of this approach for putting a corporate pandemic insurance in place.

We did not get beyond the basic principles of such a self-funded insurance scheme, and a deeper exploration of this approach would require further studies in various directions. One of them is about the drivers of the insured firm's risk aversion and the design of the insurance mechanism. We have limited ourselves to the case where the insurance coverage level corresponds to the post-pandemic value of the financial assets held by the insurer on behalf of the insured firm. If the firm's risk aversion results from an investment crowding-out mechanism under increasing marginal cost of external capital, as in the Froot et al. (1993) approach, or if it reflects bankruptcy costs, then a committed capital facility, under the form of contingent debt or equity, could meet the firm's needs more effectively, than merely covering the cash-flow losses by selling its financial assets. This would consist in adding another stage in the insurance mechanism, where the value of the assets would be traded against such an option on paidin capital. It would be worth exploring such mechanisms where a committed capital facility is bundled with asset management. Another issue is related to complementary guarantees that the insurer could provide to the insured firm, in order to reduce the uncertainty on the post-pandemic value of assets. This may go through the securitization of the residual risk, that corresponds to the difference between a guaranteed rate of return and the post-pandemic return of assets. Pandemic catbonds, issued by insurers, may be the right instrument to make such a guarantee feasible, by transferring the residual risk to dedicated investors. This suggests that the self-funded insurance mechanism that we have examined and the more traditional risk transfer through catbonds or other instruments, may have complementary roles in the coverage of the pandemic risk. 


\section{Appendix}

\subsection{Proof of Lemma 1}

A portfolio $\left\{x_{0 u}, x_{1 u}, x_{2 u}\right\}$ pays one unit of numeraire in state $u$ and zero otherwise if

$$
\begin{aligned}
& x_{0 u}\left(1+r_{f}\right)+x_{1 u}\left(1+R_{1}+h\right)+x_{2 u}\left(1+R_{2}+h\right)=1, \\
& x_{0 u}\left(1+r_{f}\right)+x_{1 u}\left(1+R_{1}-h^{\prime}\right)+x_{2 u}\left(1+R_{2}-h^{\prime}\right)=0, \\
& x_{0 u}\left(1+r_{f}\right)+x_{1 u}\left(1+R_{1}+H\right)+x_{2 u}\left(1+R_{2}-H^{\prime}\right)=0 .
\end{aligned}
$$

Solving this system of three equations with three unknowns yields

$$
\begin{aligned}
x_{0 u} & =\frac{\left(h^{\prime}-1\right)\left(H+H^{\prime}\right)+\left(h^{\prime}-H^{\prime}\right) R_{1}-\left(H+h^{\prime}\right) R_{2}}{\left(1+r_{f}\right)\left(h+h^{\prime}\right)\left(H+H^{\prime}\right)}, \\
x_{1 u} & =\frac{H^{\prime}-h^{\prime}}{\left(h+h^{\prime}\right)\left(H+H^{\prime}\right)}, \\
x_{2 u} & =\frac{H+h^{\prime}}{\left(h+h^{\prime}\right)\left(H+H^{\prime}\right)}
\end{aligned}
$$

which gives

$$
\begin{aligned}
q_{u} & =x_{0 u}+x_{1 u}+x_{2 u} \\
& =\frac{\left(H+H^{\prime}\right)\left(r_{f}+h^{\prime}\right)-\left(H^{\prime}-h^{\prime}\right) R_{1}-\left(H+h^{\prime}\right) R_{2}}{\left(1+r_{f}\right)\left(h+h^{\prime}\right)\left(H+H^{\prime}\right)} .
\end{aligned}
$$

When there are risk-neutral investors, using $\alpha_{u}=h^{\prime} /\left(h+h^{\prime}\right)$ yields

$$
q_{u}=\frac{\alpha_{u}(1-\pi)}{1+r_{f}} .
$$

Straightforward calculations with similar notations for states $d$ and $p$ yield

$$
\begin{aligned}
x_{0 d} & =\frac{(1+h)\left(H+H^{\prime}\right)+\left(H^{\prime}+h\right) R_{1}+(H-h) R_{2}}{\left(1+r_{f}\right)\left(h+h^{\prime}\right)\left(H+H^{\prime}\right)}, \\
x_{1 d} & =\frac{-\left(H^{\prime}+h\right)}{\left(h+h^{\prime}\right)\left(H+H^{\prime}\right)}, \\
x_{2 d} & =\frac{h-H}{\left(h+h^{\prime}\right)\left(H+H^{\prime}\right)},
\end{aligned}
$$

and

$$
\begin{aligned}
& x_{0 p}=\frac{R_{2}-R_{1}}{\left(1+r_{f}\right)\left(H+H^{\prime}\right)}, \\
& x_{1 p}=-x_{2 p}=\frac{1}{H+H^{\prime}},
\end{aligned}
$$


which gives

$$
\begin{aligned}
q_{d}= & x_{0 d}+x_{1 d}+x_{2 d} \\
= & \frac{\left(H+H^{\prime}\right)\left(h-r_{f}\right)+\left(H^{\prime}+h\right) R_{1}+(H-h) R_{2}}{\left(1+r_{f}\right)\left(h+h^{\prime}\right)\left(H+H^{\prime}\right)}, \\
q_{p}= & x_{0 p}+x_{1 p}+x_{2 p} \\
& \frac{R_{2}-R_{1}}{\left(1+r_{f}\right)\left(H+H^{\prime}\right)} .
\end{aligned}
$$

In particular, when there are risk-neutral investors, we have

$$
\begin{aligned}
& q_{d}=\frac{\alpha_{d}(1-\pi)}{1+r_{f}}, \\
& q_{p}=\frac{\pi}{1+r_{f}},
\end{aligned}
$$

when there are risk-neutral investors.

If (3) holds, then (29),(37) and (38) give (5). If (4) holds, then (28) and (35) give (6). Furthermore, (7),(35) and (36) yield (8).

\subsection{Proof of Proposition 1}

The first-order optimality conditions for the maximization of

$$
\begin{aligned}
\mathbb{E} u \equiv & (1-\pi) \alpha_{u} u\left(f\left(A-q_{u} y_{u}-q_{d} y_{d}-q_{p} y_{p}\right)+y_{u}\right) \\
& +(1-\pi) \alpha_{d} u\left(f\left(A-q_{u} y_{u}-q_{d} y_{d}-q_{p} y_{p}\right)+y_{d}\right) \\
& +\pi u\left(f\left(A-q_{u} y_{u}-q_{d} y_{d}-q_{p} y_{p}\right)+y_{p}-L\right),
\end{aligned}
$$

with respect to $y_{u}, y_{d}$ and $y_{p}$ are written as

$$
\begin{aligned}
(1-\pi) \alpha_{u} u^{\prime}\left(w_{u}\right) & =q_{u} \mathbb{E} u^{\prime} \\
(1-\pi) \alpha_{d} u^{\prime}\left(w_{d}\right) & =q_{d} \mathbb{E} u^{\prime} \\
\pi u^{\prime}\left(w_{p}\right) & =q_{p} \mathbb{E} u^{\prime}
\end{aligned}
$$

where we denote

$$
\mathbb{E} u^{\prime}=(1-\pi)\left[\alpha_{u} u^{\prime}\left(w_{u}\right)+\alpha_{d} u^{\prime}\left(w_{d}\right)\right]+\pi u^{\prime}\left(w_{p}\right) .
$$

Assume first that there are risk-neutral investors, i.e. (3) holds. In that case, (5) and (39)-(41) give (11), and (9),(10) show that there exists $y$ such that

$$
y=y_{u}=y_{d}=y_{p}-L .
$$

We have

$$
x_{i}=\left(x_{i u}+x_{i d}\right) y+x_{i p}(y+L) \text { for } i=0,1,2,
$$

which gives (12),(13) and

$$
x_{0}=\frac{y\left(H+H^{\prime}\right)+\left(R_{2}-R_{1}\right) L}{\left(1+r_{f}\right)\left(H+H^{\prime}\right)}=\frac{y+\pi L}{1+r_{f}} .
$$


We have $K=A-I=A-x_{0}-x_{1}-x_{2}$. Maximizing the (state-independent) final cashflow of the firm

$$
f\left(A-x_{0}-x_{1}-x_{2}\right)+y=f\left(A-\frac{y+\pi L}{1+r_{f}}\right)+y,
$$

w.r.t. $y$ gives (18).

Assume now that investors are risk-averse, i.e., (6) and (8) hold. In that case, (37)-(39) give (14) and

$$
y_{p}-L<y_{d}<y_{u} .
$$

Thus, we may write

$$
\begin{aligned}
& y_{d}=y_{u}-\Delta_{d}, \\
& y_{p}=y_{u}+L-\Delta_{p},
\end{aligned}
$$

with $0<\Delta_{d}<\Delta_{p}$. Using $y_{u}-y_{d}=\Delta_{d}>0$ gives (16), and thus (15). Using $y_{p}-L<y_{d}$ and (16) yields

$$
x_{1} H-x_{2} H^{\prime}-L<-h^{\prime}\left(x_{1}+x_{2}\right)<0,
$$

and thus

$$
L>x_{1} H-x_{2} H^{\prime}>-x_{2}\left(H+H^{\prime}\right),
$$

which gives (17). Furthermore, maximizing the firm's expected utility

$$
\begin{aligned}
\mathbb{E} u \equiv & (1-\pi) \alpha_{u} u\left(f\left(A-\frac{y_{u}}{1+r_{f}}+q_{d} \Delta_{d}+q_{p}\left(\Delta_{p}-L\right)\right)+y_{u}\right) \\
& +(1-\pi) \alpha_{d} u\left(f\left(A-\frac{y_{u}}{1+r_{f}}+q_{d} \Delta_{d}+q_{p}\left(\Delta_{p}-L\right)\right)+y_{u}-\Delta_{d}\right) \\
& +\pi u\left(f\left(A-\frac{y_{u}}{1+r_{f}}+q_{d} \Delta_{d}+q_{p}\left(\Delta_{p}-L\right)\right)+y_{u}+L-\Delta_{p}\right),
\end{aligned}
$$

w.r.t. $y_{u}$, for $\Delta_{d}$ and $\Delta_{p}$ given, yields (18), with

$$
K=A-\frac{y_{u}}{1+r_{f}}+q_{d} \Delta_{d}+q_{p}\left(\Delta_{p}-L\right)=K^{*} .
$$

\subsection{One-period model with an arbitrary number of states and assets}

This appendix presents an extended version of the model presented in Section 2.1. It is based on similar assumptions about risk aversion and technology, but with $S+1$ states, $n+1$ assets and $n \geq S$. States and assets correspond to index $s$ and $i$, respectively, with $s=0$ the pandemic state and $s=1, \ldots, S$ the

other states, and with $i=0$ the riskfree asset with return $r_{f}$, and $i=1, \ldots, n$ 
the other assets. The return of asset $i$ in state $s$ is denoted $r_{s i}$, and $f(K)$ and $L$ still denote the cashflow from productive assets and the loss in the case of a pandemic, respectively. Hence, the cashflow in state $s$ is

$$
\begin{aligned}
& w_{s}=f\left(A-\sum_{i=0}^{n} x_{i}\right)+\sum_{i=0}^{n}\left(1+r_{s i}\right) x_{i}-L \text { if } s=0, \\
& w_{s}=f\left(A-\sum_{i=0}^{n} x_{i}\right)+\sum_{i=0}^{n}\left(1+r_{s i}\right) x_{i} \text { if } s=1, \ldots, S .
\end{aligned}
$$

Let $\pi_{s}$ be the probability of state $s$, with $\sum_{s=0}^{S} \pi_{s}=1$.The firm maximizes its expected utility

$$
\mathbb{E} u=\sum_{s=0}^{S} \pi_{s} u\left(w_{s}\right)
$$

w.r.t. $x_{0}, \ldots, x_{n}$. Let $e=(1, \ldots, 1)$ be the $n+1$ dimension row vector with all components being 1 , and $r_{s}=\left(r_{s 0}, \ldots, r_{s n}\right)$. Let

$$
E=\left(\begin{array}{c}
e+r_{0} \\
\cdots \\
e+r_{s} \\
\cdots \\
e+r_{S}
\end{array}\right)
$$

be the $(S+1) \times(n+1)$ matrix, with $1+r_{s i}$ the term of row $s$ and column $i$. We assume that $E$ has full rank, and thus for all $y=\left(y_{0}, \ldots, y_{S}\right)^{\prime}$ there exists $x=\left(x_{0}, \ldots, x_{n}\right)^{\prime}$ such that $E x=y$. Let

$$
C(y)=\min \{e \cdot x \mid E x=y\},
$$

be the lowest financial investment $\sum_{i=0}^{n} x_{i}$ that provides the final payoff vector $y=\left(y_{0}, \ldots, y_{S}\right)^{\prime}$. One easily checks that function $C(y)$ is weakly convex. We assume that asset returns satisfy the no-arbitrage condition. When the representative investor is risk-neutral, the least-cost financial investment is equal to the discounted expected payoff, i.e.,

$$
C(y)=\frac{\sum_{s=0}^{S} \pi_{s} y_{s}}{1+r_{f}}
$$

while $C(y)$ is strongly convex if the representative investor is risk-averse.

The firm's expected utility is rewritten as

$$
\mathbb{E} u=\pi_{0} u^{\prime}\left(f(A-C(y))+y_{0}-L\right)+\sum_{s=1}^{S} \pi_{s} u\left(f(A-C(y))+y_{s}\right) .
$$

It is maximized w.r.t. $y=\left(y_{0}, \ldots, y_{S}\right)^{\prime}$, and an optimal portfolio of assets $x^{\prime}=$ $\left(x_{0}, \ldots, x_{n}\right)$ is such that $e \cdot x=C(y)$. The first-order optimality conditions for 
this problem are written as

$$
\begin{aligned}
\frac{\partial \mathbb{E} u}{\partial y_{0}} & =\pi_{s} u^{\prime}\left(f(A-C(y))+y_{0}-L\right)-\frac{\partial C}{\partial y_{0}} \mathbb{E} u^{\prime}, \\
\frac{\partial \mathbb{E} u}{\partial y_{s}} & =\pi_{s} u^{\prime}\left(f(A-C(y))+y_{s}\right)-\frac{\partial C}{\partial y_{s}} \mathbb{E} u^{\prime} \text { if } s=1, \ldots, S
\end{aligned}
$$

where

$$
\mathbb{E} u^{\prime}=\pi_{0} u^{\prime}\left(f(A-C(y))+y_{0}-L\right)+\sum_{s=1}^{S} \pi_{s} u^{\prime}\left(f(A-C(y))+y_{s}\right) .
$$

When the representative investor is risk-neutral, we have

$$
\frac{\partial C}{\partial y_{s}}=\frac{\pi_{s}}{1+r_{f}} \text { for all } s=0, \ldots, S,
$$

which gives

$$
u^{\prime}\left(f(A-C(y))+y_{0}-L\right)=u^{\prime}\left(f(A-C(y))+y_{s}\right) \text { for all } s=1, \ldots, S,
$$

and using $u^{\prime \prime}<0$ yields

$$
y_{0}-L=y_{s} \text { for all } s=1, \ldots, S .
$$

In other words, the financial choices of the firm provides full coverage of the pandemic loss and perfect hedging in the other states.

When the representative investor is risk-averse, we have

$$
y_{0}-L<y_{s} \Leftrightarrow \frac{\partial C / \partial y_{0}}{\partial C / \partial y_{s}}>\frac{\pi_{0}}{\pi_{s}} \text { if } s \neq 0,
$$

hence with partial coverage of pandemic losses when the marginal rate of substitution between state 0 and other states $s$ is larger than the ratio of state probabilities. 


\section{Bibliography}

\section{References}

Bartik, A. W., Bertrand, M., Cullen, Z., Glaeser, E. L., Luca, M., \& Stanton, C. (2020). The impact of covid-19 on small business outcomes and expectations. Proceedings of the National Academy of Sciences, 117(30), 17656-17666.

Buffington, C., Dennis, C., Dinlersoz, E., Foster, L., Klimek, S., et al. (2020). Measuring the Effect of COVID-19 on US Small Businesses: The Small Business Pulse Survey. Technical report.

Cummins, J. D. \& Weiss, M. A. (2013). Systemic risk and the insurance industry. In Handbook of insurance (pp. 745-793). Springer.

DBRS-Morningstar (2020). PEC Insurance: The conundrum of business interruption coverage during the Coronavirus pandemic. Technical report.

French, C. C. (2020). Covid-19 business interruption insurance losses: The cases for and against coverage. Conn. Ins. LJ, 27, 1.

Froot, K. A., Scharfstein, D. S., \& Stein, J. C. (1993). Risk management: Coordinating corporate investment and financing policies. the Journal of Finance, 48(5), 1629-1658. 